\title{
Estimation of desmosponge (Porifera, Demospongiae) larval settlement rates from short-term recruitment rates: preliminary experiments
}

\author{
Sven Zea \\ Universidad Nacional de Colombia; Apartado 10-16 (INVEMAR), Santa Marta, \\ Colombia
}

\begin{abstract}
During a study of the spatial and temporal patterns of desmosponge (Porifera, Demospongiae) recruitment on rocky and coral reef habitats of Santa Marta, Colombian Caribbean Sea, preliminary attempts were made to estimate actual settlement rates from short-term ( 1 to a few days) recruitment censuses. Short-term recruitment rates on black, acrylic plastic plates attached to open, non-cryptic substratum by anchor screws were low and variable $(0-5$ recruits/plate in 1-2 days, sets of $n=5-10$ plates), but reflected the depth and seasonal trends found using mid-term ( 1 to a few months) censusing intervals. Moreover, mortality of recruits during 1-2 day intervals was low $(0-12 \%)$. Thus, short-term censusing intervals can be used to estimate actual settlement rates. To be able to make statistical comparisons, however, it is necessary to increase the number of recruits per census by pooling data of n plates per set, and to have more than one set per site or treatment.
\end{abstract}

\section{INTRODUCTION}

For sessile marine organisms, settlement is defined as the moment a propagule attaches to the substratum and begins metamorphosis. Since a number of settlers remain "invisible" among other organisms or die before they can be found, those "visible" survivors observed at a given time are called recruits (Keough \& Downes, 1982; Wallace, 1983; Connell, 1985; Cameron, 1986). To study the sources of variation in settlement, and to answer the question of how this variation affects the distribution and abundance of adults, it is important to find a way to estimate actual settlement instead of recruitment (Connell, 1985). How close recruitment counts are to numbers actually settling depends on the temporal scale at which the observer works in relation to the scales at which settlement, growth to "visible" size, and mortality occur. To obtain actual settlement rates the observer could work on a temporal scale short enough to find most or all settled individuals before they die or disappear. For this, it is necessary to first work at a scale of magnification and on a settling surface in which it is possible to observe all settlers, "visible" or "invisible"; and second, to test whether mortality between the chosen observation times is minimal. An alternative way is to eleminate part or all the sources of postsettlement mortality, i.e. by caging to prevent predators from finding settlers; this, however, modifies the natural settling conditions to an unknown degree.

In this paper, the results of short-term (1 to a few days) censuses of desmosponge (Porifera, Demospongiae) recruitment on retrievable plates attached to the substratum in 
rocky and coral reef habitats of Santa Marta, Colombian Caribbean Sea, carried out to estimate actual settlement, are presented. These experiments were undertaken as part of a general study of spatial and temporal patterns of desmosponge recruitment (cf. Zea, 1990 and in press).

\section{MATERIALS AND METHODS}

\section{Study area}

All observations and experiments were carried out at Punta de Betín and El Morro, in the vicinity of the City of Santa Marta in the NE Colombian Caribbean $\left(11^{\circ} 15^{\prime} \mathrm{N}\right.$; $\left.74^{\circ} 13^{\prime} \mathrm{W}\right)$. The laboratory base was the Instituto de Investigaciones Marinas de Punta de Betín - INVEMAR. A description of the area is given in Zea (1990) and will be published elsewhere.

\section{General protocol}

Rectangular, $15 \times 10 \mathrm{~cm}$, coarsened, pre-soaked, black, acrylic plastic plates, attached to the substratum with a central, 1/4", anchor screw hammered into a $1 / 4^{\prime \prime}$ diameter hole and a fastening bolt, were used to study sponge recruitment. This plate shape and size were amenable to microscopic scanning and to underwater photography with the standard $35 \mathrm{~mm}$ close-up lens available. For details of this method, see Zea (1990, and in press).

Taxonomic determination of most recruits was difficult because individuals as young as this rarely contain the full spicule complement of the adults. Also, the high sponge species richness in the area (Zea, 1987) prevented identification of recruits by adult characters such as colour or major spicule types. Thus, the results of this study are based solely on the total number of sponges counted on plates.

\section{Laboratory censuses}

Whenever plates were retrieved for laboratory study, they were individually put into "Ziploc" bags and transported in seawater filled buckets (contact of plate surface with the bag was assumed to have no effect on sponge recruits). They were then kept either in aerated buckets with daily replacement of the seawater or in aquaria with filtered, running seawater. Plates were placed in a low tray with seawater, and two scans were made under the dissecting microscope to look for desmosponges. During the second scan, accumulated silt and organic debris were cleaned away with a gentle jet of water (produced by squeezing a rubber bulb attached to a Pasteur pipette) to locate sponges hidden under filamentous algae and debris. To relocate sponges in further censuses, their positions were mapped onto an acetate sheet and their colour noted.

\section{In-situ censuses}

To measure recruitment without disturbing recruits, some sets of plates were studied visually in-situ, using a simple magnifying glass, before they became heavily fouled by algae (within about the first 20-25 days of installation). Plates were also scanned twice 
underwater, cleaning away silt with a gentle jet of water from a Pasteur pipette with a rubber bulb. Then, sponges were numbered and their positions mapped with a pencil on a clean set of unattached plates. Despite the fact that counts were made in-situ this recruitment was considered "invisible", as it was believed that all demosponges had been seen in the field. However, so as not to disturb the recruits, plates were never immediately brought to the laboratory to recount the sponges under the microscope.

Short- (1 to a few days) to mid-term (1-2 months) recruitment

Initially, to determine if there was any sponge recruitment on a short-term (1-2 days) basis in two different depths, and if so, how it relates to mid-term (1-2 months) recruitment, and how much mortality occurs on this time scale, two sets of five plates each were interspersed in an area of about $2 \mathrm{~m}^{2}$ on March 30,1987, in the El Morro fringing reef, one set on the reef terrace zone ( $15 \mathrm{~m}$, series $\mathrm{H} 1)$ and the other set on the reef slope $(24 \mathrm{~m}$, series $\mathrm{H} 2)$. The deeper set was retrieved after 29 days to locate any recruited sponges in the laboratory, replaced the following day, each plate in its former place, and then retrieved again one day later to see if new sponges had settled, and if previously established recruits (those which survived laboratory manipulation) had died. The same procedure was applied to the shallower set of plates, but hoping to obtain a larger number of recruits, they were retrieved 56 days instead of 29 days after installation and were left underwater for two days between examinations instead of one. In both cases, whenever the original plates were in the laboratory, they were replaced by a new set of clean plates (series $\mathrm{HC} 1$ and $\mathrm{HC} 2$, respectively) to assay short-term recruitment on completely clean surfaces. These were then recovered and examined in the laboratory, and the original plates returned to their respective positions in the field.

In a second series of experiments, to measure short-term recruitment in-situ, ten plates were interspersed in an area of about $6 \mathrm{~m}^{2}$ in a depth of $6 \mathrm{~m}$ at the Punta de Betín rocky shore on Oct. 22, 1987 (series D). The in-situ observations were carried out 16, 17 and 23 days after installing the plates. Plates were finally retrieved for laboratory examination after 77 days. The fate of individual sponges was thus followed between day 16 and day 77. To have observations in two seasons in the same set of plates, starting Jan. 17. 1988, a clean set of plates was emplaced at the series D location, and in-situ observations of sponge recruitment were carried out as above 6 and 7 days after installation (series I, logistical problems prevented censusing this series further).

\section{RESULTS}

The short- to mid-term, invisible plate recruitment data (series H1, H2, D, I) are summarized in Table 1. Unfortunately, recruitment occurring on a single plate in 1-2 day intervals was too low and too variable (0-5 recruits) to allow statistical comparison among depths and seasons. Nevertheless, cautious comparisons are possible, keeping in mind the preliminary nature of the observations. Firstly, comparisons between short-term recruitment rates in two depths at about the same time of the year are possible between series $\mathrm{H} 1$ and $\mathrm{H} 2$, despite the fact that the initial census and the short-term interval varied between these series: Fewer sponges recruited on the shallower, reef slope terrace 
Table 1. Summary of short- to mid-term sponge plate recruitment. Data are numbers of new sponges recruited at each census (all new sponges in a census belong to a cohort). ${ }^{*}=$ counted in the laboratory, ${ }^{*}=$ counted in-situ. For details see text

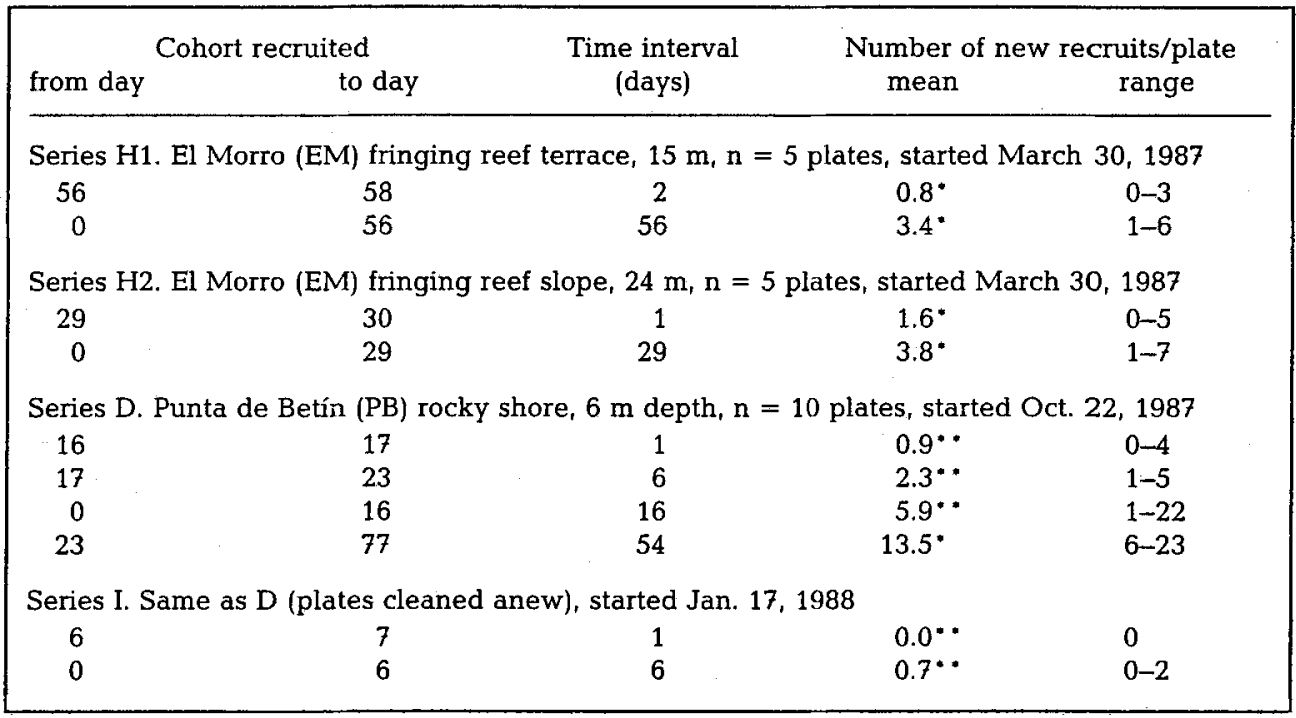

plates (series $\mathrm{H} 1,0.8$ recruits/plate in the two-day interval between day 56 and day 58) than on the deeper, reef slope plates (series H2, 1.6 recruits/plate in the one-day interval between day 29 and day 30); mid-term recruitment rates are in agreement with these presumptive habitat differences (3.4 vs 3.8 recruits/plate in 56 and 29 days, respectively; see also Zea [in press] for overall differences in mid-term recruitment between these two habitats).

Secondly, it may also be possible to compare short-term recruitment between seasons in the same site between series D and I: more sponges recruited during 1 to 6 day intervals on series D plates (between Oct.-Nov. 1987, rainy season) than on series I (Jan. 1988, dry season; 0.9 vs 0.0 and 2.3 vs 0.7 recruits/plate for 1 and 6 days, respectively). See Zea (in press) for seasonality of sponge recruitment in the area. However, it is not known if the relatively low recruitment on the latter series occurred because the plates were still too clean (underwater only for 6 days versus 16 days on series D). Nevertheless, series I exemplifies the problem of using a time interval of only one day whenever recruitment rates are low.

Short-term recruitment did occur both on relatively clean plates (series D-I) and on those already colonized by algae (series $\mathrm{H} 1-\mathrm{H} 2$ ). However, no sponges recruited to the $\mathrm{HC} 1$ and $\mathrm{HC} 2$ series on completely clean plates within the first two days of emplacement (data not shown in Table 1).

The number of days survived by each cohort in which it was possible to follow the fate of its recruits is given in Table 2 . For all cohorts, survivorship was relatively high $(88 \%$ to $100 \%$ ) between the first and the second censuses (the second census was within one or two days of the first). This was true whether plates were brought to the laboratory (series $\mathrm{H} 1$ and $\mathrm{H} 2$ ) or were scanned underwater (series D and I). Over slightly longer 
Table 2. Short- to mid-term survivorship of recruits. Plate series are those of Table 1. Data are total (all plates pooled) numbers of surviving recruits [percentage] at each census. One cohort each was followed for series I, H1 and H2, and three for series D

\begin{tabular}{|c|c|c|c|c|c|}
\hline \multicolumn{2}{|c|}{ Cohort recruited } & \multicolumn{4}{|c|}{ Census } \\
\hline from day & to day & 1 & 2 & 3 & 4 \\
\hline & & (Day 56) & $\begin{array}{r}\mathrm{Se} \\
(\text { Day } 58)^{\circ}\end{array}$ & & \\
\hline \multirow[t]{2}{*}{0} & 56 & $\begin{array}{c}17 \\
{[100]}\end{array}$ & $\begin{array}{c}15 \\
{[88.2]}\end{array}$ & & \\
\hline & & (Day 29) & $\begin{aligned} & \mathrm{Se} \\
& \text { (Day 30) }\end{aligned}$ & & \\
\hline \multirow[t]{3}{*}{0} & 29 & $\begin{array}{c}19 \\
{[100]}\end{array}$ & $\begin{array}{c}17 \\
{[89.5]}\end{array}$ & & \\
\hline & & \multicolumn{4}{|c|}{ Series D } \\
\hline & & (Day 16) & (Day 17) & (Day 23) & (Day 77) \\
\hline 0 & 16 & $\begin{array}{c}59 \\
{[100]}\end{array}$ & $\begin{array}{c}54 \\
{[91.5]}\end{array}$ & $\begin{array}{c}40 \\
{[67.8]}\end{array}$ & $\begin{array}{c}11 \\
{[18.6]}\end{array}$ \\
\hline 16 & 17 & & $\begin{array}{c}9 \\
{[100]}\end{array}$ & $\begin{array}{c}9 \\
{[100]}\end{array}$ & $\begin{array}{c}2 \\
{[22.2]}\end{array}$ \\
\hline \multirow[t]{2}{*}{17} & 23 & & & $\begin{array}{c}23 \\
{[100]}\end{array}$ & $\begin{array}{c}11 \\
{[47.8]}\end{array}$ \\
\hline & & \multicolumn{4}{|c|}{ Series I } \\
\hline 0 & 6 & $\begin{array}{c}17 \\
{[100]}\end{array}$ & $\begin{array}{c}17 \\
{[100]}\end{array}$ & & \\
\hline - Plus one & laborc & & & & \\
\hline
\end{tabular}

periods (6-7 days), whereas $100 \%$ of the sponges of series $D$ which had recruited between day 16 and 17 survived to day 23 (a 6 -day period), only $67.8 \%$ of those that recruited between day 0 and day 16 survived to day 23 (a 7-day period). Mid-term survivorship (through the 54-day period between the third and fourth censuses, series D) ranged only between $18.6 \%$ and $47.8 \%$.

\section{DISCUSSION}

Only in some species of barnacles, oysters, gastropods, bryozoans and ascidians have measurements been made of short-term (hours to 1-3 days) recruitment rates, thanks to their relatively large larve, settlement in open substrata, and in some cases, their leaving attached remains for some time after death (review in Connell, 1985). Sponge larvae are generally large (0.1-2 mm; Wapstra \& van Soest, 1987), and thus, recently settled individuals are easily detected in the field on relatively clean surfaces, or under the dissecting microscope on retrievable plates (Zea, in press). Most sponge recruitment studies, however, have been made on a temporal scale of several weeks to months (e.g. 
Hartman, 1958; Wells et al., 1964; Bergquist \& Sinclair, 1973; Reiswig, 1973; Fell, 1976a, 1976b; Dayton, 1979; Ayling, 1980; Barthel, 1986). The shortest time scale was used by McDougall (1943) who found for the sponge Reniera tubifera weekly means of up to 26 recruits $/ 100 \mathrm{~cm}^{2}$ ( $\mathrm{n}=18,116 \mathrm{~cm}^{2}$ tiles on a piling at North Carolina, USA) during the June-July reproductive period. At Santa Marta, however, means of only between 0.4 and 2.1 sponges $/ 100 \mathrm{~cm}^{2}$ recruited on the exposed substrata of the rocky shore during one week ( $\mathrm{n}=10$ plates, series I and D, Table 1) in January 1988 and November 1987, respectively. These differences in weekly rates are probably due to the greater abundance of sponges (and hence, sponge recruits) which usually exists in shaded pilings or shaded rocky overhangs, relative to open and well illuminated, subtidal substrata (Zea, in press), where the observations described here were carried out.

Sponge recruits were indeed recorded at censusing intervals of 1 or 2 days, but only in periods when heavy recruitment was occurring. Longer intervals are thus needed to have at least a few attached larvae on plates during periods of low recruitment. However, with regard to each plate, short-term rates were too low and variable to allow for statistical comparisons in the design used here. The same problem was faced when midterm rates were measured at Santa Marta in sets of $n=4-12$ plates, obtaining medians of 1-27 sponges $/ 100 \mathrm{~cm}^{2}$ for sampling periods ranging from 20 to 77 days (Zea, in press). To solve this problem, it is suggested to pool numbers of all $\mathrm{n}$ plates forming a single set to obtain a single data point. To have replicates, thus, several sets of $n$ plates should be emplaced for each site/habitat/treatment.

As is the case for many, if not all sessile animals, there was no recruitment onto completely clean plates within the first 1-2 days underwater at Santa Marta (series HC1 and HC2). Thus, for sponge recruitment to occur, the substratum probably must be "precoated" by an organic, bacterial and/or microscopic algal film (e.g. Crisp \& Ryland, 1960; Crisp, 1974; Bergquist, 1978). A few days later, however, short-term rates may differ according to the extent to which algae have colonized on plates. To test for this effect, sets of plates would have to be installed at different dates, and short-term recruitment censuses carried out simultaneously in all sets. For mid-term intervals (30 to 70 days), Zea (1990) found that recruitment rates were similar whether plates started clean or were heavily fouled by crustose and filamentous algae, because all plates ended equally fouled after about 1-2 months. These results indicate that if there is an algal effect on sponge recruitment, it occurs within the first few days.

Recruitment rates measured at short time intervals (hours to a few days) could be considered good estimators of actual settlement rates, assuming that post-settlement mortality is near zero over this interval. At Santa Marta, this latter assumption was tested with positive results (0-12\% at $1-2$ day intervals) for both relatively clean and heavily fouled plates, during periods of heavy as well as low recruitment, and even when plates were brought to the laboratory, a procedure which did not seem to increase mortality of recruits. Moreover, mid-term mortality rates of 53-81\% (54 days) found in this study are in agreement with those of other studies: Fell \& Lewandrowski (1981) for the sponge Halichondria sp. on eelgrasses in New England found that $81 \%$ of individuals between 1 and $10 \mathrm{~mm}$ in diameter died within 4 weeks. Similarly, Hartman (1958), found $56.4 \%$ of recruited Haliclona loosanoffi in New England died within the first month. In other studies, Zea (1990) found that $77.6 \%$ of sponges which recruited onto four plates during one year at El Morro rocky shore died within the first month after recruitment, and Zea (in 
press) found recruit mortalities between $51.1 \%$ and $89.5 \%$ during a two-month period at six rocky and coral reef habitats of El Morro.

Thus, provided that the above mentioned problem of low and variable number of recruits/plate is solved by using more than one set of $n$ plates, estimation of actual settlement rates in sponges can be carried out as described here. Although it is logistically very difficult to make comparisons of sponge settlement and recruitment across habitats and seasons, one could monitor recruitment on a monthly or bi-monthly basis in combination with simultaneous short-term $(1-2$ or $2-6$ days as estimators of actual settlement) censuses on the same sets of plates. It is advisable to maintain the algal carpet on the plates, thereby allowing them to mimic the natural substratum and the seasonal changes which occur on it, and thus, plates should be brought to the laboratory for microscopic examination.

Acknowledgements. This paper is part of a dissertation presented in partial fulfillment of the requirements for the Ph.D. Degree, Division of Biological Sciences, The University of Texas at Austin, USA, under the kind advice of J. C. Lang (Texas Memorial Museum). Financial support for this research comes from the US National Science Foundation - NSF (INT-8611717 to J. C. Lang and S. Zea), the Instituto Colombiano para el Desarrollo de la Ciencia y la Tecnología 'Francisco José de Caldas' - COLCIENCIAS (CO 2105-09-03-86 to S. Zea) and the Instituto de Investigaciones Marinas de Punta de Betín - INVEMAR (220-95 to S. Zea). I convey my thanks to INVEMAR and its personnel for their logistical support. Living expenses while carrying out the field work at Santa Marta were facilitated by a Houston Seaspace Scholarship, A University of Texas Graduate School Fellowship, and a COLCIENCIAS Doctoral Student Aid. The Universidad Nacional de Colombia permitted me to spend half of my working time in the data analysis and writing. I am indebted to N. L. Fowler (Dept. Botany, Univ. Texas Austin) for her statistical advice.

\section{LITERATURE CITED}

Ayling, A. L., 1980. Patterns of sexuality, asexual reproduction and recruitment in some subtidal marine Demospongiae. - Biol. Bull. mar. biol. Lab., Woods Hole 158, 271-282.

Barthel, D., 1986. On the ecophysiology of the sponge Halichondria panicea in Kiel Bight. I. Substrate specificity, growth and reproduction. - Mar. Ecol. Prog. Ser. 32, 291-298.

Bergquist, P. R., 1978. Sponges. Hutchinson, London, 268 pp.

Bergquist, P. R. \& Sinclair, M. E., 1973. Seasonal variation in settlement and spiculation of sponge larvae. - Mar. Biol. 20, 35-44.

Cameron, R. A., 1986. Introduction to the invertebrate larval biology workshop: a brief background. - Bull. mar. Sci. 39, 145-161.

Connell, J. H., 1985. The consequences of variation in initial settlement vs. postsettlement mortality in rocky intertidal communities. - J. exp. mar. Biol. Ecol. 93, 11-45.

Crisp, D. J., 1974. Factors affecting the settlement of marine invertebrate larvae. In: Chemoreception in marine organisms. Ed. by P. I. Grant \& A. M. Mackie. Acad. Press, New York, 177-265.

Crisp, D. J. \& Ryland, J. S., 1960. Influence of filming and surface texture on the settlement of marine organisms. - Nature, Lond. 185, 119.

Dayton, P. K., 1979. Observations of growth, dispersal and population dynamics of some sponges in McMurdo Sound, Antarctica. In: Biologie des Spongiaires. Ed. by C. Lévi \& N. Boury-Esnault. Colloques int. Cent. natn. Rech. scient. 291, 271-282.

Fell, P. E., 1976a. Analysis of reproduction in sponge populations: an overview with specific information on the reproduction of Haliclona loosanoffi. In: Aspects of sponge biology. Ed. by F. W. Harrison \& R. R. Cowden. Acad. Press, New York, 51-67.

Fell, P. E., $1976 \mathrm{~b}$. The reproduction of Haliclona loosanoffi and its apparent relationship to water temperature. - Biol. Bull mar. biol. Lab., Woods Hole 150, 200-210. 
Fell, P. E. \& Lewandrowski, K. B., 1981. Population dynamics of the estuarine sponge, Halichondria sp., within a New England eelgrass community. - J. exp. mar. Biol. Ecol. 55, 49-63.

Hartman, W. D., 1958. Natural history of the marine sponges of southern New England. - Bull. Peabody Mus. nat. Hist. 12, 1-155.

Keough, M. J. \& Downes, B. J., 1982. Recruitment of marine invertebrates: the role of active larval choices and early mortality. - Oecologia 54, 348-352.

McDougall, K. D., 1943. Sessile marine invertebrates of Beaufort, North Carolina. A study of settlement, growth, and seasonal fluctuations among pile-dwelling organisms. - Ecol. Monogr. $13,321-374$.

Reiswig, H. M., 1973. Population dynamics of three Jamaican Demospongiae. - Bull. mar. Sci. 23, 191-226.

Wallace, C. C., 1983. Visible and invisible coral recruitment. In: Proceedings of the Great Barrier Reef Conference. Ed. by J. T. Baker, R. Carter, P. W. Sammarco \& K. Starck. James Cook Univ. Pr., Townsville, 259-261.

Wapstra, M. \& Soest, R. W. M. van, 1987. Sexual reproduction, larval morphology and behavior in demosponges from the southwest of the Netherlands. In: Taxonomy of the Porifera. Ed. by. J. Vacelet \& N. Boury-Esnault. Springer, Berlin, 281-307.

Wells, H. W., Wells, M. J. \& Gray, I. E., 1964. Ecology of sponges in Hatteras Harbor, North Carolina. - Ecology 45, 752-767.

Zea, S., 1987. Esponjas del Caribe Colombiano. Dictyoceratida, Dendroceratida, Verongida, Haplosclerida, Poecilosclerida, Halichondrida, Axinellida, Desmophorida y Homosclerophorida. Catálogo Científico, Bogotá D. C., 286 pp.

Zea, S., 1990. Distribution, cover and recruitment of demosponges (Porifera, Demospongiae), in rocky and reefal habitats of Santa Marta, Colombian Caribbean, Diss., Univ. Texas, Austin, 154 pp.

Zea, S., 1992. Recruitment of demosponges (Porifera, Demospongiae), in rocky and coral reef habitats of Santa Marta, Colombian Caribbean. - Mar. Ecol. 13 (4) (in press). 